\title{
Empowering Teachers' Professionalism for Students' Better Learning through Reflective Training: A Theoretical Framework for Sustainable EFL Teacher Professional Development
}

\author{
Gunadi Harry Sulistyo, Sri Rachmajanti, Suharyadi \\ English Department \\ Universitas Negeri Malang \\ Malang, Indonesia \\ gunadi.hs@gmail.com
}

\author{
Siti Muniroh \\ Faculty of Education \\ Monash University \\ Melbourne, Australia
}

\begin{abstract}
This paper aims at proposing a theoretical framework for a training platform developed for English language teacher professional development in the context of Indonesia. This proposed frameworks motivated by the concern on the existing training practices that tend to thus far have affected on students' learning English not impressively as expected. Such a phenomenon takes place attributable to the training practices aimed at professionalizing teachers that regrettably adopts a 'hit-and-run' cascade modus: once an educational reform is introduced to teachers, they are then let go on their own. In the present proposed training framework Reflective Training - more down to earth and on-in-on mentoring is offered while providing ample spaces for the teachers to actualize their teaching strategy contextually and then reflect their actualization. The framework is designed to scaffold teachers collaboratively with strategies in recognizing actual problems of students' learning in their class, formulating the problems, locating the causes, designing best solutions to the problem through innovative instructional strategies, reflecting the implementation, theorizing their innovative strategies, and sharing the strategies through an online journal specifically designed to disseminate their teaching innovation. In addition, online a learning resource is designed to provide them with an interactive medium for them to communicate real-time among themselves as well as with mentors and experts to discuss matters pertaining to optimizing students' learning along the planning, implementing, and reflecting stages. The framework is developed with a view to substantially changing English teachers upon joining the training mainly in their English teaching-related affection attributes and their cognition ones that will guide them ultimately with prudence to perform effective teaching delivery to affect students' learning in due course.
\end{abstract}

Keywords-Reflective, Training, Mentoring, Collaboration, Innovation

\section{INTRODUCTION}

It is an undeniable fact that teachers conceptually play a key role in classroom learning activities [1]. In active studentoriented learning context, teachers play a number of significant roles as the controller of learning activities, implementers of the government policy, facilitators of students' learning, managers of their class activities, and counselor to the students' learning needs. As a controller, teachers' main task teacher is to direct or determine student-learning activities. As the implementer of learning activities, teachers should be able to ensure that students learn and proceed in their learning activities along the line the lesson plan teachers have planned. As a manager or monitor, the teacher's responsibility is to design learning, control time, control learning activities to achieve learning objectives, conduct assessment and feedback activities. As a facilitator or a simulator, teachers must be good at motivating students so that students can perform learning activities effectively and efficiently. As a counselor, a teacher serves as a source of advice for learning activities that students need. These roles and functions are challenging.

With the demands of these roles and functions, a teacher must continually strive to develop themselves professionally using a variety of ways, both formally and informally. However, it is argued, teachers are commonly of the belief that they are merely implementers of the government's policy. They are positioned as an object to instructional responsibilities as instructed. As a result, they feel they never have the chance to voice their experience, let alone have their freedom to celebrate their success. In fact, they have roles, responsibilities, and at the same time the natural right to actualize their innovative ideas and be rewarded appropriately. Thus far, the government and our community have more on demands on teachers than rewards while rewards impact positively on teachers' performance [2].

In fact, teachers also need to be flexible along the way through their teaching career, as innovations in education will dynamically advance and never end and so will their students' learning needs as well as the government policies. Teachers must be always ready to adopt, adapt, or create teaching strategies that are in line with technological advances, developments, and innovations in education in general as well as the ever-evolving real-life needs and the ever-changing policies of the government. With the launch of the 2013 
Curriculum, for instance as a kind of educational innovation, teachers are also required to understand, respond appropriately, and implement it properly and correctly in accordance with the regulation of the Indonesian Ministry of National Education (MoNE) No. 65 of 2013 on Process Standards. The ultimate end is their teaching effectiveness to equip students with necessary English skills required to face the 21st century challenges. However, based on monitoring, evaluation and supervision activities during the period of $2013-2015$ conducted by the present researchers in their involvement as trainers and mentors in the early phases of the implementation of K-13, not all teachers who were involved in the training on Curriculum 2013 were able to apply the Curriculum 2013 properly as expected. Saddening empirical evidence even indicates a dark side in the implementation of the national curriculum. Ahmad discovered among other things that teachers tend to interpret the newly introduced curriculum - K13 - partially based on their own conceptions and understanding [3]. As a result, from the planning stage to the assessment one they still tended to use the old paradigm of teaching principles. Suharyadi revealed another gloomy picture that with the genre-based approach learning innovation only partially a small number of teachers $(9.25 \%)$ understood, let alone mastered and applied the government policy appropriately upon the time the government introduced the socalled Curriculum 2004 for about 9 years [4].

In addition, the regulation presents the concepts of the learning process of Curriculum 2013 as an innovation in education as follows: The Process Standards that were originally focused on Exploration, Elaboration, and Confirmation were supplemented by Observing, Referring, Processing, Presenting, Concluding, and Creating. In addition, learning occurs not only in the classroom, but also in the school and community. Also, teachers are not the only source of learning. Next, attitude is not taught verbally, but through real examples in daily behaviors. To implement the above concepts requires a qualified teacher. Conceptually, the government innovative policy described previously is considered relevant to equip students with the demands of the 3rd millennium competences. However, observations and results of previous research as described previously indicate several inadequate points in the introduction of innovations made by the government for the improvement of teacher competences. This governments' effort seems to have inconsequential and impactful power to change teachers' teaching practices at school levels. The root of such inefficiency and ineffectiveness can be traceable to a number of factors, one of which is the training practices conducted by the government for teacher empowerment in the classroom. There are several factors pertaining to teacher training matters. First, there seems to be inefficient training strategies due to lack of inter-institutional coordination among government institutions responsible for district-level education. Secondly, innovations in learning introduced by the government do not reach the intended target optimally. Next, even the objectives of the information received are not well understood. Furthermore, there is resistance in teacher's mindset to curriculum changes. Teachers still tend to be unable to leave their teaching practices from the old paradigm [5].
Further, a survey conducted through observations and questionnaires point out the following disadvantages [4]. First, training is less intensive and teachers tend to be more receptive to theory than to direct practice. Secondly, the modeling of learning activities is inadequate, and often non-existent. Third, the training materials are inadequate and discuss more the theory not the practical needs in the classroom. In addition, the training materials covered tend to be general and too many. This results in the teacher is less focused and do not understand. Fourth, the training time is too short or limited and is implemented when the teacher is fasting during Ramadan. Fifth, there are insufficiently intensive follow-up activities after the teacher joins the training. Sixth, the trainers do not fully cope with the materials presented so that the teachers are less enthusiastic in the training to complete.

The conditions described previously should not have taken place, which affects undesirably students' learning. That is, the government's effort to improve the competence of the teachers ultimately has slight impacts on student learning. In other words, the central role of teachers in learning as mandated in Law no. 14 year 2005 articles 9 and 10 and Law no. 16 year 2007 on teacher standard of qualifications and competences is not optimal to achieve its target. If this continues to happen repeatedly without a systematic solution, eventually student learning will turn out to be ineffective and inefficient. If this happens, the preparation of Indonesian human resources from a functional mastery of English in preparing the Indonesian gold generation, facing the ASEAN Economic Community (MEA) and meeting the demands of the 3rd millennium will be systematically disrupted. In response to the issues described above systematic, conceptual and planned efforts are needed to systematically solve problems. This piece of writing is proposed conceptually to solve the problem in the context of Indonesia, which we label is as Reflective Training for English Teachers. The situation described above shows that, despite the government's effort to quality EFL teaching practices in class, there has been disharmony or even disconnection between numerous innovative efforts introduced by the government and their implementation at school levels.

Reflective training is a proposed training model that is expected to solve the problems described previously at the Indonesian context. Reflective Training is a model of training that seeks to refine past training models that various parties have conducted. The training focuses on providing facilitation to teachers starting from training to on-the-site assistance based on contextual identification and analysis of the issues in the school context as well as reviewing strategies appropriate to the problem locally. From the results of the study formulated problem solving conceptually. This Reflective Training empowers trained teachers who are assets in the governmental levels of districts and cities in the Indonesian context. Training and assistance in the school-level start from learning planning, which then proceeds to observation or observation, implementation, evaluation and finally reflection. The impact of the process is expected to foster the belief that the trainees can design a lesson that is thought to be able to solve the problems faced locally in their classroom. The belief is reinforced by dispensing scientifically with systematic, conceptual, empirical, and normative thoughts to be further 
disseminated to colleagues through blogs, research-based seminars and scientific journals through continuous mentoring. Provision of continuous supports is essential while we hand over responsibility to teachers to take it fully for their further sustainable growth. It is our belief that students need great teachers as great teachers create great learning environments that could lead them favorably to their learning needs. Great teachers are those that are well informed of pedagogical and professional matters that enable them to facilitate students' learning effectively in an inspiring learning environment. This kind of training model is to be conducted in various schools with different characteristics in the districts /cities in Indonesia. Great teachers are professional teachers who are effective in their teaching so that their classroom teaching impacts positively students' learning. In Indonesian context, teacher professionalism is the requirement for teachers as mandated by the Government Law on Teacher and Lecturer Competences no 14 year, 2005. Therefore, teachers must always update themselves continuously to make them more empowered in their facilitating students' learning in the classroom to face the 21 st century competences.

\section{TeACHER PRofessional DEVELOPMENT}

According to OECD, professional development refers to a whole series of well-planned activities incorporating initial training, induction courses, in-service training, and continuous professional formation within school settings in order to prepare teachers for their profession [6]. This definition implies that professional development is a deliberate action taken to empower teachers' attributes in their profession so that they are more competent as a teacher. This definition also implicitly identifies that teachers are positioned in a dual role as both a learner and a practitioner [7]. This entails that in teacher professional development activities teachers simultaneously serve as both an object and a subject of training. As an object of training, teachers are the ones of which qualification is being upgraded; as a subject, teachers are assumed to be an active participant in all activities set during the training. In the definition there implies also an assumption that the existing teacher's competences are no longer sufficient to cater for the ever-changing needs of students, educational reforms, and other contextual advances. Finally, professional development is conducted beyond pre-service training activities; that is, it is carried out when teachers are on duty. Thus, professional development may take the form of in-service and on-service trainings.

Teacher professional development aims at a number of objectives. Quint echoes the focus by the experts in education that teachers need to be professionally developed in two main areas: subject-matter mastery and/or instructional-delivery capabilities [8]. This scope of objectives is broad in nature. Kowalchuk observes that continuous professional development for teachers may undergo three types of technical patterns [9], i.e., the technical-developmental perspective, the subject matter orientation, and ecological interpretation of learning to teach. Meanwhile, OECD specifies the area of concern of teacher development pertaining to hands-on classroom immediate needs. In the first place, teacher development serves as a medium for teachers to upgrade their internal traits such as making them informed about recent advances in the subjectmatter content, to improve their teaching skills, alter their attitudes and redefine their approaches to teaching in line with the progress of teaching techniques and objectives, and new educational research. In addition, teacher development also enables them to adapt and to implement instructional changes required in the curricular reforms introduced to them. It is also a medium for teachers to exchange ideas among colleagues and experts. Finally, professional development also enables instructionally low-performing teachers to be better professionally.

Professional development for teachers may also embrace a wider scope of purposes. There are a number of forms of professional training aimed at improving teachers' knowledge and skills (http://edglossary.org/professional-development/). In the first place, teachers can promote their understanding of theoretical advances in their subject-matter area. Improvement in their knowledge widens their understanding and thus provides them with chances to redefine their conception of the subject-matter substance. An example of this is the introduction of Systemic Functional Grammar concepts in which the grammar of text is used to replace their conception of the grammar of form. The emergence of CLIL (Content Language Integrated Learning) introduces English teachers to the importance of teaching English across curriculum. A good example of this is the introduction of thematic teaching, or sheltered teaching [10]. Teachers may also get the benefit of updating their teaching strategies for classroom purposes. Recently, the government introduces the scientific approach to teaching subject matter to teachers. Although at the beginning of its introduction, this new approach to teaching causes confusions among teachers and invites arguments among educational experts, to some extent this approach leads to academic discussions that open new perspectives for teachers to experiment and use teaching techniques differently in the classroom.

Professional development may also aim at providing teachers with opportunities to get them officially certified. Certification programs nationally held are examples for this objective of professional development. Professional development also aims at enabling teachers to use their analytical skills for identifying roots of learning problems on the students' part and using the results as a basis to align their teaching strategies with students' learning needs. Advances in ICT require that teachers be literate in technological matters and make use of its advantage for learning purposes. Teacher workshops on the use of Edmodo for instance, or computerized item analysis are examples of professional development dealing with promotion of teachers in technological skills. Effective class management for stimulating students' critical thinking may also be another objective of professional development. Lesson study workshops are among examples of such professional development. Collaborative or interdisciplinary teaching provides the opportunities for English teachers to teach classes in teams with teachers from other disciplines as it happens in adjunct EFL teaching in which English teachers and content-area teachers team up carrying out instructional activities together [11]. Professional development also creates an opportunity for new teachers and 
experienced ones to interact for taking and giving constructive feedback. New teachers can learn from their senior teachers in a collegial mentoring scheme. A tandem teaching collaboration is a possible form of this activity.

A form of collaboration recently introduced to teachers aims at providing them with knowledge and skills in performing classroom action research. In such a training teachers learn how to professionalize themselves by identifying problems in their class, tracing the causes of the problems, developing rational teaching strategies to solve the problems, implementing the strategies, collecting evidence for what works and what does not work in implementing the strategies, and finally reflecting the results.

Other aims of joining professional development are certification and further degree earning. Certification provides teachers with an opportunity to make teachers keep up with recent advances in teaching practices and theories and government policies for them to implement in the classroom. Upon joining such a certification program, a teacher is then certified, a kind of recognition as a professional teacher. Considered to be a more academic professional development, pursuing a degree for a teacher commonly constitutes a more challenging activity. Teachers need to spend more time and energy doing the activity on campus, thus leaving for some time their workplace.

Effective professional development programs are highly desirable; otherwise they are a waste of time and resources. However, not all professional development programs are effective in equipping teachers with necessary competences needed in instructional real classroom context. In order for professional development activities to be operative in improving teachers' competences in their teaching job, several conditions are crucial. Richardson argues that professional development is considered effective when it shares several features [12], four of which are worth noting here. In the first place, professional development takes time. In addition, subsequent activities should follow, aiming at enhancing skills and knowledge introduced in the previous activities. Unlike the training for teacher professional development commonly carried out as a hit-and-run activity, effective professional development need to be subsequently followed up with other ancillary activities once it is started. In addition to this, professional development is not a matter of instructions from a master to a servant in which inequality of responsibility and power exists. An effective professional development is the one in which power and responsibility is shared equally between the mentor and the trainees. That is, training activities need to promote collegiality. Teachers as trainees come with varied beliefs and practices in joining a professional training program. An effective professional development activity accepts the fact of such diversity in teachers' beliefs and practices. Professional trainings are not meant to make participants uniform in beliefs and practices. Considering that teacher beliefs play a vital tool in promoting educational practices, professional development needs to accommodate the existence of such different beliefs and practices [6], [13], [14]. It is argued that appreciating differences in teachers' beliefs and practices is essential [15], the aim of which is to support educational reforms introduced to teachers that necessarily come with perspectives different from the elements of the reforms. Finally, effective professional development involves external mentors or facilitators. Teacher regular forums at a district level involve facilitators among teachers themselves who are considered to have more knowledge or skills. However, using external mentors or facilitators offers teachers several pluses. External mentors provide participants with different angles in dealing with an issue. In addition, external mentorships offer a sense of accompaniment to teachers in facing educational reforms. In addition, external mentoring enhances the growth of creativity on the parts of the teachers as reforms are offered from different perspectives [16].

Why do teachers need to develop professionally in their teaching career? We can use several angles to respond to that question. Two are worth addressing here: students' side and teachers' perspective. On students' side, obviously students' learning needs to be of high quality while high quality learning stems from knowledgeable and skilled teachers with competent expertise. Furthermore, considering the crucial role of a teacher, students cannot grow appropriately in their English competences without sufficient facilitation of great teachers as Vygotsky has put it to theorize [17]. Students - no matter their attributes are - in the hand of great teachers are with the right persons to learn better. These teachers will guide and take their students to their right learning needs for their lives. Students' learning needs also considerably differ from their era. For instance, $\mathrm{Z}$ generations differ in their learning needs from the needs of baby-boomers from which teachers come. Unless teachers make themselves adapted to their students' learning needs, teachers of a generation different from that of the students may encounter challenges that can hinder their teaching effectiveness.

On teachers' perspectives, learning is necessarily an everlasting process. So, when someone, including teachers, graduates from their education, it does not mean that they have to stop learning. They need to qualify themselves along the way in their profession upon graduation. Therefore, continuous learning let alone for teachers or anyone in professional occupations is inevitably crucial. In teacher professional development, teachers need to be aware themselves that they are in the position as learners. Secondly, although they get education from colleges with assumed functional sufficient knowledge and skills for future jobs, these competences are not sufficient for them to function properly in their new school jobs. In other words, well-planned pre-service trainings for teachers do not guarantee that teachers will be prepared for all the challenges they will face throughout their careers. School teaching demands vary substantially from one place to another place, which college education cannot always meet completely. Thirdly, innovations for instance ICT use in the classrooms and advances in learning theories, as well as government policies change dynamically over time. All these mean that teachers should inescapably encounter. They need to deal with these changes by making themselves catch up with these changes properly.

Mizell exerts that teachers who do not get professional development in their career will not expand their competences appropriately [18]. When this happens, students will get the impacts as teachers will not satisfactorily meet their students' 
learning and their students' learning will seriously agonize ultimately. Several previous studies reviewed by Marzano demonstrated that teacher professional development conducted on important educational variables pertaining to teachers teaching aspects impacts positively on students' learning achievement [19]. A similar findings are observed by Jackson and Bruegeman [20]. Considering these points described previously, therefore, teachers need further professional supports in their profession.

\section{MODELS OF TEACHER PROFESSIONAL DEVELOPMENT PROGRAMS}

Several teacher professional development programs conceptually exist and are in use [21]. In terms of the dispensation, the first model is the cascade model or the trainthe trainer model. In this model, selected competent teachers probably master teachers - are trained at the central level. During the training of the trainers, their skills and knowledge from central training are then passed to the teachers at the next lower level and so on until they are trained to the teachers at the lowest level as the recipient of the educational innovation. For instance, the activity starts from the training of the competent trainers at the national level. Upon receiving national training, the national trainers pass the knowledge and skills to the next trainers at the provincial level. The provincial level trainers then train teachers at the district level.

The next model is the teacher-centered model. In this model, as its name indicates, the focus of attention is on a teacher performance that becomes the object of learning. Under the teacher-centered model, Burns mentions five more models of teacher professional development: Observation/Assessment, Open Classrooms, Lesson Study, Study Groups, Looking at Student Work (LSAW) [22]. In the observation /assessment model, an experienced teacher observes a teacher teaching in a class, assesses the teacher's teaching performance, and then conducts a post-teaching discussion with the teacher under observation. In the next model, open classrooms provide opportunities for teachers to observe the performance of other experienced teachers who develop a lesson plan. The observers are not involved in the lesson planning. Upon teaching activities, the experienced teacher shares his /her experience with the observers in a discussion session upon teaching. Lesson study is another model of teacher development. In this model, teachers work together to make a lesson plan. One of the teachers then implements the collaborative plan in the classroom. Other teachers observe the students' learning behavior as a response to the learning activities designed in the lesson plan. Upon teaching activities, they discuss evidence in the students' learning based on the lesson plan tested in the class. An expert commonly attends the discussion also. In another model - study groups - as its name suggests, teachers get together formally to discuss issues they encounter during the planning or the implementation of the planning. The aim is to solve shared problems to arrive at a common solution. The key element of this model is the whole process that involves teachers to study a problem through a number of activities: reviewing sources, discussing the issue, and doing reflections. An expert is involved during the discussion. The last model pays attention to the assessment of students' work - Looking at
Student Work (LSAW) that is conducted as formative assessment. Based on the students' work, collaboratively teachers review the planning of the lesson implemented on which students' formative performance is examined. Thus, the process goes back from students' performance to teachers' planning through a study conducted collaboratively to examine what the implementer has performed and what he/she has not.

Meanwhile, there are also other professional development models as viewed from the initiatives: standardized training, school-based training, and self-directed training. Standardized training models are those commonly carried out nationwide. In such a model, the central government develops a professional development scheme by a team of experts or experienced teachers. The model is centralized in terms of the initiative, policies, provision of resources, and implementation. It recruits experienced trainers to be deployed as the trainers in the training conducted regionally. Therefore, they take uniform procedures in the training activities that are implemented to different regions or districts. In Indonesian context, a good example for this kind of training model is the introduction of Curriculum 2013 (K-13) to teachers nationally.

The school-based training initiatives come from local school schools. However, the resources such as the expertise, facilitators, and the training materials are supplied from the facilitators. Schools invite facilitators considered knowledgeable in skills needed by teachers in the schools and they normally provide the facilitator with necessary facilities for the training to be conducted at school levels. Thus, the skills and knowledge to be trained to teachers vary depending on the needs of individual schools. A similar form of such a training is district-level trainings organized by a district level government in which several teachers of schools in a district under a teacher discussion forum gather to professionalize themselves through training activities facilitated by invited experts or experienced teachers. The materials are hands-on ready for immediate class implementation. Therefore, school based-training or district-based training normally last for one or two days.

Individual teachers may be in compelling needs of special skills and knowledge in particular areas that their individual several teacher professional development programs conceptually exist and are in use [21]. In terms of the dispensation, the first model is the cascade model or the trainthe trainer model. In this model, selected competent teachers probably master teachers - are trained at the central level. During the training of the trainers, their skills and knowledge from central training are then passed to the teachers at the next lower level and so on until they are trained to the teachers at the lowest level as the recipient of the educational innovation. For instance, the activity starts from the training of the competent trainers at the national level. Upon receiving national training, the national trainers pass the knowledge and skills to the next trainers at the provincial level. The provincial level trainers then train teachers at the district level.

The next model is the teacher-centered model. In this model, as its name indicates, the focus of attention is on a teacher performance that becomes the object of learning. Under the teacher-centered model, Burns mentions five more models 
of teacher professional development: Observation/Assessment, Open Classrooms, Lesson Study, Study Groups, Looking at Student Work (LSAW) [22]. In the observation /assessment model, an experienced teacher observes a teacher teaching in a class, assesses the teacher's teaching performance, and then conducts a post-teaching discussion with the teacher under observation. In the next model, open classrooms provide opportunities for teachers to observe the performance of other experienced teachers who develop a lesson plan. The observers are not involved in the lesson planning. Upon teaching activities, the experienced teacher shares his /her experience with the observers in a discussion session upon teaching. Lesson study is another model of teacher development. In this model, teachers work together to make a lesson plan. One of the teachers then implements the collaborative plan in the classroom. Other teachers observe the students' learning behavior as a response to the learning activities designed in the lesson plan. Upon teaching activities, they discuss evidence in the students' learning based on the lesson plan tested in the class. An expert commonly attends the discussion also. In another model - study groups - as its name suggests, teachers get together formally to discuss issues they encounter during the planning or the implementation of the planning. The aim is to solve shared problems to arrive at a common solution. The key element of this model is the whole process that involves teachers to study a problem through a number of activities: reviewing sources, discussing the issue, and doing reflections. An expert is involved during the discussion. The last model pays attention to the assessment of students' work - Looking at Student Work (LSAW) that is conducted as formative assessment. Based on the students' work, collaboratively teachers review the planning of the lesson implemented on which students' formative performance is examined. Thus, the process goes back from students' performance to teachers' planning through a study conducted collaboratively to examine what the implementer has performed and what he/she has not.

Meanwhile, there are also other professional development models as viewed from the initiatives: standardized training, school-based training, and self-directed training. Standardized training models are those commonly carried out nationwide. In such a model, the central government develops a professional development scheme by a team of experts or experienced teachers. The model is centralized in terms of the initiative, policies, provision of resources, and implementation. It recruits experienced trainers to be deployed as the trainers in the training conducted regionally. Therefore, they take uniform procedures in the training activities that are implemented to different regions or districts. In Indonesian context, a good example for this kind of training model is the introduction of Curriculum 2013 (K-13) to teachers nationally.

The school-based training initiatives come from local school schools. However, the resources such as the expertise, facilitators, and the training materials are supplied from the facilitators. Schools invite facilitators considered knowledgeable in skills needed by teachers in the schools and they normally provide the facilitator with necessary facilities for the training to be conducted at school levels. Thus, the skills and knowledge to be trained to teachers vary depending on the needs of individual schools. A similar form of such a training is district-level trainings organized by a district level government in which several teachers of schools in a district under a teacher discussion forum gather to professionalize themselves through training activities facilitated by invited experts or experienced teachers. The materials are hands-on ready for immediate class implementation. Therefore, school based-training or district-based training normally last for one or two days.

Individual teachers may be in compelling needs of special skills and knowledge in particular areas that their individual teaching activities require. On their own initiatives, they intentionally join a training to upgrade themselves. In such a case, the training is categorized as self-directed training. Recently a long with advances of information and communication technology, online trainings are available to serve teachers with specialized instructional needs. For instance discusses a number of professional development of teachers through such distance learning modes [23].

Apart from the types of professional training described previously, there are also other forms of professional development as seen from praxis angles which Ling puts it to say as field experience-based training [24]. These are 'the apprenticeship, professional, mentorship, and some modified models of professional-internship, inter-professional' [24].

In brief, professional development programs come with varied models. Teacher professional development may be seen in general in terms of the modus of training delivery, the initiator, and the kind of learning experiences. Each model has their own aims; yet they overlap. In addition, these models also provide angles on which to synthesize and to innovate concepts for further training to envisage.al teaching activities require. On their own initiatives, they intentionally join a training to upgrade themselves. In such a case, the training is categorized as self-directed training. Recently a long with advances of information and communication technology, online trainings are available to serve teachers with specialized instructional needs. For instance discusses a number of professional development of teachers through such distance learning modes [23].

Apart from the types of professional training described previously, there are also other forms of professional development as seen from praxis angles which Ling puts it to say as field experience-based training [24]. These are 'the apprenticeship, professional, mentorship, and some modified models of professional-internship, inter-professional' [24].

In brief, professional development programs come with varied models. Teacher professional development may be seen in general in terms of the modus of training delivery, the initiator, and the kind of learning experiences. Each model has their own aims; yet they overlap. In addition, these models also provide angles on which to synthesize and to innovate concepts for further training to envisage.

\section{RESULTS AND DISCUSSION}

This section discusses the previous professional training development program ever practiced that may be taken as some lessons learned. The government of the Republic of Indonesia 
through MoNE has attempted to improve the quality of English teachers not only at the national and but also at the regional levels. These trainings adopt different models with some modifications. However, no valid and formal sources that describe or report these trainings can be accessed. In addition, no empirical evidence is available on the level of success of these trainings so no judgment can be drawn from the implementation of these trainings. The following account describes briefly some professional development trainings once implemented in Indonesia.

First, the government once ran the training on the implementation of the present Kurikulum 2013. The legal and formal basis for the trainings conducted successively among other things is for instance on the government regulation c/o MoNE no. 24, year 2016. An instance of such training is the Directorate of Management of the Lower Secondary Education has performed top-down trainings. The training starts by running first the Training of Trainers (ToT) for national instructors (NIs) who are comprised of selected experienced teachers and lecturers. These national training participants joined a 60-hour training program for six consecutive days (Guideline of Directorate of Management of the Lower Secondary Education, 2017) in which they learn through lecturing activities and discussions [25]. The materials of the training include the government policies, basic competences, and instructional approaches. Upon the training, these Nis induce the knowledge and skills to the provincial instructors for curriculum development (PIs) in 50-hour trainings for about five consecutive days in the provincial training levels. These PIs then train district/city instructors (DIs) in the same training format and contents. Ultimately, these district/city instructors (Dis) guide teachers at the targeted schools with their knowledge and skills they learn from the previous training attended. In fact, Dis perform collegial mentoring at the school implementation when these teachers apply the knowledge and skills on the new government policies at the class level. At the district level, the mentoring activities are carried out in the onin-on format in which collaboratively they plan, act, and reflect the teaching practice on the innovation. In some cases, the targeted schools later introduce the new policies they learn to other non-targeted schools around the targeted schools. Through this cascade model of training, the government intends to reach more schools with the new policy under teacher professional development trainings.

Secondly, through the aid scheme projects supported by among other things the Asian Development Bank (ADB) and USAID Decentralized Basic Education (or DBE USAID), teacher professional development programs were developed aiming at improving elementary school science and math teachers' teaching competences particularly in targeted provinces. Unlike the government's initiatives described previously, these projects invite educational experts of regional universities and experienced teachers who are selected on the projects' criteria to involve in the activities like preparing the training modules and developing instructional strategies of student active learning under the expertise collaboration with the sponsors' experts, and facilitating teachers during the workshops.
Upon the training, these master teachers depart to targeted clusters in which several teachers gather to carry out the trainings for cluster teachers under the facilitation of these master teachers, university experts, and the experts representing the project management. At the end of each training session, they hold reflection sessions. To support the implementation of the instructional strategies, every cluster has a learning center with a library and an internet access in it for teachers in the clusters to have intensive communication for teachers across clusters to exchange experiences and ideas on professional matters.

Thirdly, higher educational learning institutions are also concerned with teacher professional development. For instance, Universitas Negeri Malang through UPT P2LP carries out trainings for teachers with international standards. Prior to training activities, UPT P2LP conducts needs assessment activities by visiting schools under the supervisory management of UPT2LP with the aim observing classroom activities and all teaching kits provided by teachers. Based on the needs assessment, experts of UPTP2LP then design a training program for teachers and develop training materials. Teacher trainings under UPT P2LP are conducted yearly in three days. Teachers experience planning and peer teaching activities during the training activities. Upon the training sessions, they implement their knowledge and skills in their own class. Routinely (twice in a year), UPT2LP monitors, evaluates, and supervises the progress while providing feedback.

Next, there is another form of training known as CICTT (Cambridge International Certificate for Teachers and Trainers). Under this training scheme, before the training activities begin, teachers interested in joining the training sign up a commitment contract to actively participate in all activities set up from the beginning to the end in in-training activities, which are set up to last for 6 consecutive days. This training program equips teachers with classroom teaching skills using practice-based courses. Therefore, at the end of the training, teachers are to conduct research based on their own classroom issues.

Several more training activities in fact have been conducted throughout the country. This writing will not report all however. Apart from the impact of these trainings, this is not officially available, on teacher teaching effectiveness in the classroom, these trainings aim at professionalizing teachers with a varied scheme of training activities. There are several lessons learned from the previous training practices on the management side in fact. In the first place, teacher professional development programs need to be highly structured in order to facilitate teachers optimally in their learning of necessary knowledge and skills needed for their class. With such a clear structure of training activities, participants enable to get the maximum benefit of the training. In addition, in-service teachers are in need of practical matters pertaining to indigenous class needs. Therefore, hands-on materials touching particular classroom needs are essential for training program providers to consider. Teachers tend to be submissive and obey in terms of performing innovations introduced to them. Therefore, there is a compelling need in providing them with a room to for them to actualize themselves academically by 
creating innovations emanating from their classroom practice, reflecting their success and failure, and then disseminating their innovations as the best practice and (worst failures) to be shared with colleagues. This way, teachers will have a word to voice based on their personal academic experiences. Experiential learning and reflecting activities on innovations therefore needs prioritizing in facilitating teachers during professional training. Moreover, innovations to classrooms come and go fast as these are facts teachers face in their job, and frequently they are left overwhelmed in such a circumstance. Therefore, stimulating teachers to be sustainably responsive to such changes by mentoring and coaching them academically is crucial. Technological advances provide flexible access to such academic and continued supports to teachers so that these avoid teachers from being illiterate in a broad sense. In addition, making them aware that they need in an unrelenting state as learners is also an angle for teacher training program developers to consider in professional development activities.

\section{REFLECTIVE TRAINING AS EVIDENCE-BASED FRAMEWORK}

In their roles and responsibilities, teachers constantly face a number challenges that call for immediate solutions. In response to the needs to empower teachers in their profession which are rooted to their local school context, the present article proposes a theoretical framework that may be utilized as a basis on which to run an effective teacher professional training program. Such a framework essentially scaffolds teachers in performing well and effectively in their daily activities. Just as McKenzie argues for scaffolding for students' learning sake, scaffolding teachers for teachers' instructional sake in the form of an effective professional development program also provides several advantages [26]. Such a program provides teachers with clear visions, missions, and targets. In other words, the program sets clear directions. The program clarifies purposeful accomplishment of tasks during the training. Teachers are aware of what to achieve and how to achieve them. When the program clarifies its purpose, it will not only keep teachers focus on tasks and direct teachers to ample learning sources worth attending to but also offer teachers reflective assessment modes to clarify expectations. Clear professional development programs furthermore enable us to convey them efficiently. In addition, scaffolding through clear professional development programs reduces vagueness, disbelief, and dissatisfaction on the teachers' part. Most importantly, systematic scaffolding creates the right impetus and reasons for teachers to qualify themselves professionally.

The present framework adopts the philosophical ground for learning as proposed by Vygotsky's constructivist sociocultural theory of learning. Vygotsky's theory provides us with corridors within which teacher professional development trainings can be conducted. The main ideas of his theory lie in these precepts: learning takes place first before development; language constitutes our main thinking device to learn; the main corridor to learning is facilitation; learning and development takes place within social collaboration; and the key space within which learning occurs is the Zone of Proximal Development (ZPD) [17]. Promoting teachers professionally is essentially a function of these ideas put into actual practice systematically that enable teachers make meanings out of their profession [27].

The present framework is developed on the following underlying beliefs. Within Borg's concept [13], cognitively, teachers are readily to take a role as continuous learners and at the same time reflective practitioners [7]. Furthermore, teachers will be more empowered professionally when they take risks unlearning past and outdated beliefs, and learning new contents and pedagogy. Next, teachers will develop their teaching better if their teaching is based on their experiential and reflective learning modes. That is, teachers can achieve learning to teach better and better day-by-day through doing things on principled and research-based knowledge. Furthermore, collegial scaffolding, mentoring, and coaching constitute the key to teacher professional development activities. Not only knowledgeable and resourceful teachers are a key to student's better learning, but also enthusiastic teachers with right visions of standards to achieve affect students' learning positively. Finally, ICT access and access to ICT provide teachers with a tool to be illiterate academically.

There are several guiding principles in use in this present framework. First, teachers are autonomous and reflective learners. Yet, scaffolding them professionally is still necessary to some extent they need until after they can firmly stand on their own. Teacher professional development activities are essentially a medium in which teachers are to be equipped with the right tools to identify their own problem, formulate the problem accurately, make a decision by using sound solutions, implement strategies, reflect and theorize the innovation, and share the innovation with a broad spectrum of audience. Furthermore, as Guskey and Knight [28], [29] argue, in order for professional development trainings to be considered effective, they should affect teachers at least in three areas: their cognitive attributes: understandings, beliefs, attitudes, and values on teaching and learning; their classroom teaching practices; and their student learning outcomes.

Furthermore, the principles adopted in the present framework reflect findings of the study [30], [31]. The principles also echo a research-based and critical synthesis by Hunzicker [32], who lists important characteristics of effective teacher professional development activities, several of which are worth adopting as the section that follows outlines. With reference to the scope, professional development training may focus on two main areas: content and pedagogy as Quint has previously described [8], the effect of which improves students' learning. In addition, classroom challenges vary naturally across teachers. In other words, while the cases are individual, individual experiences also provide different teachers with useful lessons they can learn. Therefore, development training needs to satisfy not only their individual teaching needs but also offers to teachers a medium to share experiences. It should be both personalized and mutual. This also follows that teacher professional development activities need to engage teachers physically, cognitively, and emotionally in an active and interactive learning environment that gives them chances to collaborate with others to identify and formulate problems, trace the sources of the problems, make decisions to create innovations, and implement the innovations. Furthermore, elements of reflections should 
become the concern of professional trainings for teachers. Teachers have the opportunity to see whether their teaching delivery plan works or does not work, identify which works and which does not, and locate the areas that cause failures and those that lead to success. Training needs to be reflective. With such a reflective element, professional trainings should equip teachers with necessary skills to enhance their inquisitiveness pertaining to challenges in their classroom practice, and to satisfy their inquiry empirically. Finally, professional trainings should be aligned to teachers' daily roles and responsibilities. Trainings are for students' learning. However, both teacher training and classroom activities need to be connected within natural classroom culture.

In terms of delivery, the present framework takes the following elements: collegial coaching, mentoring, collaborative teamwork, assessment and reflection, and flipped class activities. In addition, the present framework recognizes teachers with different levels of competence: novice, competent, expert/professional teachers. These arguments described above are roughly theoretical however. Empirical evidence on the soundness of the framework needs to be sought through further studies.

In other words, teacher trainings in the future necessarily contain elements of teachers' application of knowledge, orientation to practicing and doing, active participation, reflection, self-actualization, and alignment to classroom activities. Future trainings adopting the framework need to be conducted using step-by-step-delivery strategies in which collegial coaching, mentoring, collaborative teamwork, assessment and reflection, and flipped class activities are exerted. In addition, future teacher development should also take the best advantage of technological advances in information and communication

Reflective training as a professional development training aims at developing a learning culture for quality teaching for English teachers of the Indonesian national in their the teaching competences through continuing and reflective learning opportunities undertaken collaboratively to meet the local teaching needs with a view to meeting the ever-changing needs of students' learning for their learning improvement

As individuals in functioning in their roles and responsibilities, upon joining the training adopting the framework are expected to be highly professionally spirited in having their autonomy and taking the best choice to solve problems in their class with sound and always updated knowledge and skills empirically substantiated. In addition, teachers need to be reflective, that is they can self-replenish their teaching capability based on empirical evidence so that they affect students' learning positively.

\section{CONCLUSION}

Thus far, teacher trainings in the context of teacher professional development have been characterized as the 'onesize-fits-all', uni-modal (i.e. lecturing), theoretical, and hit-andrun format. As a result, teachers never have a chance to implement the knowledge and skills they learn from trainings they attend appropriately. Therefore, such training models need to be avoided in order to shun ineffectiveness and failures.

\section{REFERENCES}

[1] S. Shamsudin and H. R. Karim, "Implementation of focus on form: teachers' and students' conceptions," Procedia-Social Behav. Sci., vol. 70, pp. 1265-1274, 2013.

[2] N. Shakir and S. Zamir, "Impact of Rewards on Teachers' Performance at Secondary Level," J. Educ. Pract., vol. 5, no. 10, pp. 101-105, 2014.

[3] D. Ahmad, "Understanding the 2013 Curriculum of English Teaching through the Teachers' and Policymakers' Perspectives," Int. J. Enhanc. Res. inEducational Dev., vol. 2, no. 4, pp. 6-15, 2014.

[4] S. Rachmajanti, G. H. Sulistyo, and Suharyadi, "English Teacher Professional Development Training Practices: Lesson learned from Indonesian Context," in ISoLEC Proceedings (forthcoming), 2017.

[5] T. Sumadi, "Kebijakan, Filosofi dan Pengembangan Kurikulum," in National Trainers Training, 2015.

[6] OECD, "Teaching and Learning International Survey 2008 Technical Report," 2010.

[7] D. A. Schön, Educating the reflective practitioner: Toward a new design for teaching and learning in the professions. San Francisco: JosseyBass, 1987.

[8] J. Quint, "Professional Development for Teachers What Two Rigorous Studies Tell Us," 2011. [Online]. Available: https://www.mdrc.org/publication/professional-development-teachers. [Accessed: 21-Jun-2017].

[9] E. A. Kowalchuk, "Perceptions of practice: What art student teachers say they learn and need to know," Stud. Art Educ., vol. 41, no. 1, pp. 7190, 1999.

[10] D. Freeman and Y. Freeman, "Sheltered English instruction.ERIC Digest ED301070," 1998. [Online]. Available: http://thememoryhole.org/edu/eric/ed301070.html. [Accessed: 07-Sep2017].

[11] D. M. Brinton, M. A. Snow, and M. B. Wesche, Content-based Second Language Instruction. New York: Newbury House, 1989.

[12] V. Richardson, "The dilemmas of professional development," Phi delta kappan, vol. 84, no. 5, pp. 401-406, 2003.

[13] S. Borg, "Teacher cognition in language teaching: A review of research on what language teachers think, know, believe, and do," Lang. Teach., vol. 36, no. 2, pp. 81-109, 2003.

[14] L. Xu, "The role of teachers' beliefs in the language teaching-learning process," Theory Pract. Lang. Stud., vol. 2, no. 7, pp. 1397-1402, 2012.

[15] D. Scott and R. Gani, "Engaging Student's Prior Knowledge in the Social Studies and History Classroom," in Paper presented at The Canadian Society for the Study of Education Annual Conference, 2016.

[16] D. Dalton, "6 immediate benefits of an external mentor," 2015. [Online]. Available: https://3plusinternational.com/2015/04/6-immediate-benefitsexternal-mentor/. [Accessed: 17-Jul-2017].

[17] A. Walqui, "Scaffolding instruction for English language learners: A conceptual framework," Int. J. Biling. Educ. Biling., vol. 9, no. 2, pp. 159-180, 2006.

[18] H. Mizell, "Why Professional Development Matters," 2010.

[19] R. J. Marzano, What works in schools: Translating research into action. ASCD, 2003.

[20] C. K. Jackson and E. Bruegmann, "Teaching Students and Teaching Each Other: The Importance of Peer Learning for Teachers," Cambridge, 15202, 2009.

[21] E. Gaible and M. Burns, "sing Technology to Train Teachers: Appropriate Uses of ICT for Teacher Professional Development in Developing Countries," Washington, DC: infoDev / World Bank, 2005. [Online]. Available: http://www.infodev.org/articles/using-technologytrain-teachers. [Accessed: 26-Sep-2017].

[22] M. Burns, "Five Models of Teacher-Centered Professional Development," Global Partnership for Education, 2014. [Online]. Available: https://www.globalpartnership.org/blog/five-models-teachercentered-professional-development. [Accessed: 26-Nov-2014]. 
[23] M. Burns, Distance education for teacher training: Modes, models and methods. Washington, DC: Education Development Center, Inc, 2011.

[24] L. Y. Ling, "Underpinnings of teachers' professional development-a new conceptualization of field experience," Asia Pacific Educ. Rev., vol 4, no. 1, pp. 11-18, 2003.

[25] M. of E. and C. (Indonesia), "Guideline of Directorate of Management of the Lower Secondary Education." Jakarta, 2017.

[26] J. McKenzie, "Scaffolding for Success," Educ. Technol. J., vol. 9, no. 4, 1999.

[27] S. McLeod, "Lev Vygotsky," Simply Psychology, 2014. [Online]. Available: https://www.simplypsychology.org/vygotsky.html. [Accessed: 07-Sep-2017].
[28] T. R. Guskey, "Professional development and teacher change," Teach. Teach., vol. 8, no. 3, pp. 381-391, 2002.

[29] P. Knight, "A systemic approach to professional development: learning as practice," Teach. Teach. Educ., vol. 18, no. 3, pp. 229-241, 2002.

[30] A. Lieberman and D. H. P. Mace, "Teacher learning: The key to educational reform," J. Teach. Educ., vol. 59, no. 3, pp. 226-234, 2008.

[31] H. E. Quick, D. J. Holtzman, and K. R. Chaney, "Professional development and instructional practice: Conceptions and evidence of effectiveness," J. Educ. Students Placed Risk, vol. 14, no. 1, pp. 45-71, 2009.

[32] J. Hunzicker, "Characteristics of Effective Professional Development: A Checklist," Online Submiss., 2010. 